\title{
Commentary: Searching for the golden fleece-How do you repair damaged myocardium?
}

\author{
Victor A. Ferraris, MD, PhD
}

From the Department of Surgery, University of Kentucky, Lexington, Ky.

Disclosures: Author has nothing to disclose with regard to commercial support.

Received for publication June 28, 2019; accepted for publication July 1, 2019; available ahead of print Aug 13, 2019.

Address for reprints: Victor A. Ferraris, MD, PhD, University of Kentucky, A301 Kentucky Clinic, 740 S Limestone, Lexington, KY 40536-0284 (E-mail: ferraris@uky.edu).

J Thorac Cardiovasc Surg 2020;159:2273-4

$0022-5223 / \$ 36.00$

Copyright (C) 2019 by The American Association for Thoracic Surgery

https://doi.org/10.1016/j.jtcvs.2019.07.014

The idea that stem cell transplantation may be able to repair or replace damaged myocardium is the "golden fleece" that has intrigued investigators for more than 30 years. This interest started with mouse embryos and ultimately led to the discovery, in 1998, of a method to derive stem cells from human embryos and to grow the cells in the laboratory. These cells are called human embryonic stem cells and have served as a source of stem cells for research for at least 20 years. More recently, researchers identified conditions that allow some specialized adult cells to be "reprogrammed" genetically to assume a stem cell-like state. The Nobel prize was awarded to Gurdon and Yamanaka in 2012 for their work in the discovery that mature human cells can be reprogrammed into human pluripotent stem cells (hiPSCs). There are many potential applications that could use hiPSCs (Figure 1). One particularly attractive possibility for hiPSCs is their use in regenerating injured myocardium or replacing myocardial damage that consists of nonfunctioning postinfarct scar.

Like many ideas in medicine and surgery, the concept that hiPSCs can simply be injected into damaged myocardium to fix the problem of postinfarct injury is clear, simple, and wrong. ${ }^{1}$ In this issue of the Journal, Aoyama and coauthors ${ }^{2}$ lay out the expanded picture of what is necessary for hiPSCs to provide reparative properties to injured or nonfunctioning myocardial cells. Aoyama and coauthors ${ }^{2}$ answer the question of how you define mature cardiomyocytes in culture. They point out that electrophysiologic, genetic, and functional analyses are necessary to evaluate maturation. Many studies have investigated the efficiency of generating and characterizing hiPSC-derived cardiomyocytes. These generated cells are often immature with regard to biochemical, physiologic, and morphologic properties and consist of arterial, ventricular, and nodal cells. Consequently, these cells beat asynchronously in various directions, resembling embryonic cardiomyocytes, and tend to be arrhythmogenic. Maturation is an essential element for hiPSCs to transform into functioning myocardial cells. The key element in this process is to define mature functioning cardiomyocytes. In

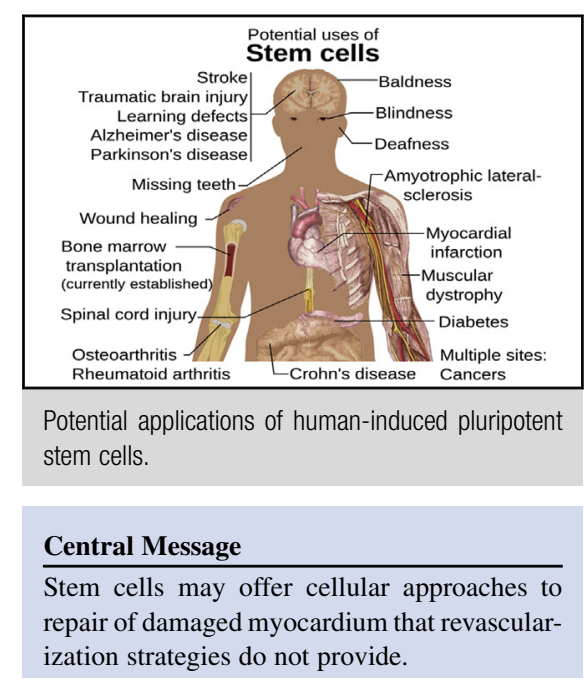

See Article page 2260.

concise terms, that is exactly what the Aoyama and coauthors $^{2}$ did. I confess that the experimental details are elusive at best, and confusing or obscure at worst, to most cardiothoracic surgeons, me included. Suffice it to say that this study provided the basis for generation of functional cardiomyocytes that contract synchronously and set the stage for future studies that include delivery systems that use biomaterials for transplantation into animals and eventually into humans.

It is worth speculating how the mature myocardial cells created and characterized by Aoyama and coauthors ${ }^{2}$ might be introduced into damaged or destroyed myocardium. Creation of a viable functioning myocardial cell is the initial and essential first step. A subsequent step includes delivery of mature myocardial cells into the target (damaged or destroyed myocardium). The list of delivery methods is vast and includes such exotic things as microporous iron oxide scaffolds, ${ }^{3,4}$ electrospun nanofibers, ${ }^{5}$ and antibody-armed platelets to direct stem cells to injured myocardium. Further, it may be helpful to speculate on the optimal source of hiPSCs. Some authors suggest that spermatogonial stem cells provide some optimal characteristics that are ideal for regenerative purposes. ${ }^{7}$ It is likely that other delivery methods, alternative sources of stem cells, and optimal stem cell maturation characteristics will provide ideal circumstances for regeneration of damaged myocardium. Clearly, more work needs to be done, but future studies and applications offer very attractive possibilities for treatments of damaged myocardium. 


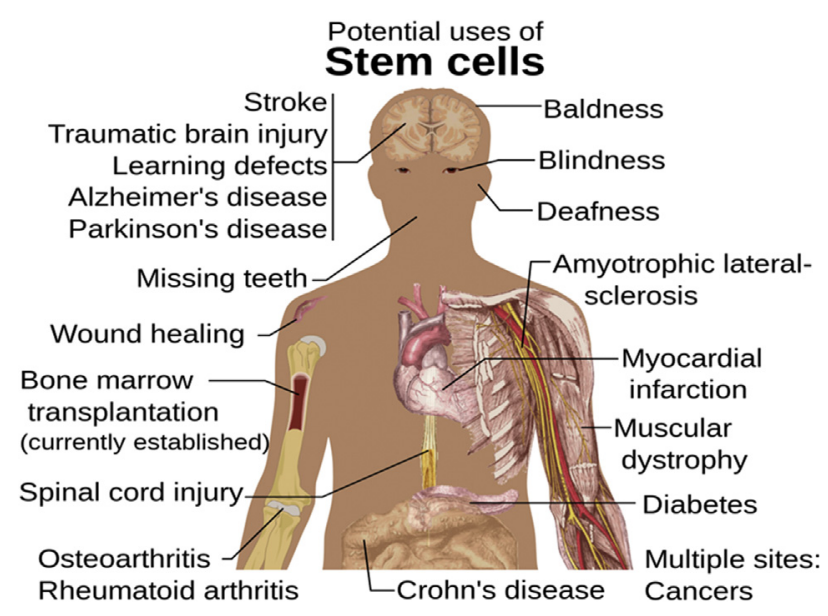

FIGURE 1. Potential applications of human induced pluripotent stem cells.

\section{References}

1. Ferraris VA, Shander A. Commentary: Is transfusion as simple as Goldilocks makes it? "For every complex problem there is an answer that is clear, simple, and wrong." J Thorac Cardiovasc Surg. 2020;159:976-7.

2. Aoyama J, Homma K, Tanabe N, Usui S, Miyagi Y, Matsuura K, et al. Spatiotemporal imaging documented the maturation of the cardiomyocytes from human induced pluripotent stem cells. J Thorac Cardiovasc Surg. 2020;159:2260-71.e7.

3. Yang H, Wei L, Liu C, Zhong W, Li B, Chen Y, et al. Engineering human ventricular heart tissue based on macroporous iron oxide scaffolds. Acta Biomater. 2019; 88:540-53.

4. Pattar SS, Fatehi Hassanabad A, Fedak PWM. Acellular extracellular matrix bioscaffolds for cardiac repair and regeneration. Front Cell Dev Biol. 2019;7:63.

5. Arumugam R, Srinadhu ES, Subramanian B, Nallani S. $\beta$-PVDF based electrospun nanofibers - a promising material for developing cardiac patches. Med Hypotheses. 2019;122:31-4.

6. Shen D, Li Z, Hu S, Huang K, Su T, Liang H, et al. Antibody-armed platelets for the regenerative targeting of endogenous stem cells. Nano Lett. 2019;19: 1883-91.

7. Mardanpour P, Nayernia K, Khodayari S, Khodayari H, Molcanyi M, Hescheler J. Application of stem cell technologies to regenerate injured myocardium and improve cardiac function. Cell Physiol Biochem. 2019;53:101-20. 